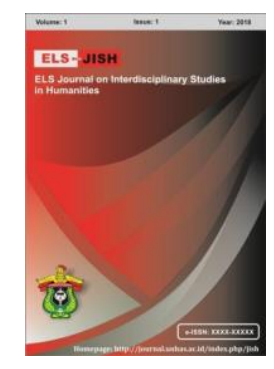

ELS-JISH

ELS Journal on Interdisciplinary Studies on Humanities

Volume 3 Issue 4, 2020

ISSN (print) : 2621-0843

ISSN (online) : 2621-0835

Homepage : http://journal.unhas.ac.id/index.php/jish

\title{
A Socio-Pragmatic Analysis of Social Media Comments on Online Learning at the Time of COVID 19
}

\author{
Fatima Abdul Ghany Idrees ${ }^{1}$, Atyaf Hasan Ibrahim² ${ }^{*}$ \\ 2atyafatyaf2000@yahoo.com
}

\begin{abstract}
The fundamental aim of the present study is to analyze the pragmatic aspects of the English social media comments on posts related to online learning at the time of Covid19. The aim in this socio-pragmatic study is to identify the maxims and strategies used by English commenters and the extent to which the commenters follow or flout these and strategies when commenting on posts related to online learning at time of COVID 19. It also aims at investigating how the social media, as a new marvelous vital trend, contributes to increase language and linguistic variation in people's online comments. To achieve these the researchers analyze 25 Facebook comments based on two adopted models; Grice's (1975) maxims and Crystal's strategies (2001) to build a comprehensive picture about the role of age, gender, social status on the comments. The results of the analysis show that both models are applicable and sometimes flouted. Some commenters flout more than two maxims in the same comment and the same is true regarding Crystal's model. It has been found that comments are highly constrained by social factor, while age and gender do not have great significant effect.
\end{abstract}

Keywords: socio-pragmatic analysis, online learning, Covid19, social media comments. Strategies and maxims.

How to cite: Idrees, F. A. G., \& Ibrahim, A. H. (2020). EFL A Socio-Pragmatic Analysis of Social Media Comments on Online Learning at the Time of COVID 19. ELS-Journal on Interdisciplinary Studies in Humanities, 3(4), 638-650. DOI: https://doi.org/10.34050/elsjish.v3i4.11525

\section{Introduction}

Deadly virus has appeared and spread all around the world, obviously it interrupts all aspects of human's lives, hence each country tries as much as possible to take measures, among these are schools and universities which have been closed and people isolated themselves from the external world. Online learning replaced traditional learning hence which divided people into two groups; supporters and rejecters. Baron (2001:1) and Crystal (2001:275) clarify the fact that virtual world and online communication has completely changed the way of communication locally and globally.

${ }^{1}$ College of Education for Human Sciences, University of Diyala, Iraq 
Kollock and Smith (1999:8) show the complexity and ambiguity process to distinguish the online comment's features behind the commentator's point of view since it differs from face to face conversation through which we can distinguish people from their age, gender, educational background, physical appearance, voice and so on, while in online communication there is a lack of many signals.

Studies on the role of online learning from various perspectives are recent and emerging studies, hence there are little studies, for instance, Pozgaj and Knezevic (2007) in " E-Learning: Survey on Students' Opinions" through it, they made a survey to collect student's opinions about the ability to use E-learning system as a supplement to traditional learning, eventually they concluded that E- Leaning is a vital form of education and that will soon have to be used everywhere. Goyal and Malhotra (2013) at "Role of Online Education in Modern Education System", discuss the essential role of online Learning in education and the advantages of it to create more flexible learning and make the traditional learning more interesting .They concluded that learners the center of the process and have to change their thinking from traditional learning to more innovative one.

The present study aims at: 1) Investigating the social media comments through which people express their point of view about the role of online learning at the time of COVID19; 2) Investigate to what extent the social variables such as (level of education and gender) have effect on people's comments; 3) Identify which maxims and strategies are most followed or flouted.

\section{Review Related Literature}

\subsection{Online learning and its synonyms}

In the past, traditional learning (face to face communication) was given a central place, but nowadays E-learning is the major way of learning. Faisal et al (1999:1) describe class room learning as an old method to get knowledge through which the learner finds himself with difficult situations and the lack of interactive training aids makes difficult for learners to cope up with new ideas. Therefore, there is a need to create a more open system, a new trend that is capable of getting others' attention.

Anderson (2008:xii ) points out that traditional learning is essential for many years, but people nowadays are so immersed in technology and it becomes the most obvious thing used throughout the world. Prensky (2001:4) illustrates this by saying that the good leader should know how to communicate with his employee by using their language, knowing their interest and styles, so dealing with the virtual world becomes so crucial since it is the matter of the world and all the learners have great interesting this field as well as humans who are thirsty for getting learning via more motivated ways, virtual world can provide population with more knowledge especially at the emergency time when it is difficult to go to school.

Othman etal (2012:454) and Surjono etal. (2017:783) clarify the reasons of using online learning that provides people with the opportunity to access an 
infinite number of channels, variety materials and skills a lifelong to anybody, anytime, and anywhere especially those who are disable to attend the real lecture according to (age, time, etc.).

On his part, Baten etal (2009:4) describes the role of online learning from a pragmatic framework to show that there is a need to deal with the topic from six angles:

1. Concept. It deals with the strategic future insight for online learning and how the view of distance learning will change as well as look for online as a way to foster interaction and communication among people in a global context,.

2. Training (administer) is to recognize the certain needs of the learner and choose the optimal and suitable material therefor and as a result the learner can change from saying to doing.

3. Content. It is the most important dimension; it talks about the material, the approach and the methodology of the study, the ability of the instructor to clarify the material, taking into consideration the language use, attitude, culture and language variation

4. Culture and attitude. It is very important to provide the comfortable climate to study at any time and place, through the rest and through work

5-Coordination and control or (planning and management skills) of encompassing framework of online learning.

Urdan and Weggen (cited in Surjono, 2017:783) mention the fact that there are many alternative names for online learning. They clarify these types of online learning and how the last one is considered as a part of Distant Education; Computer-Based, virtual classroom, Virtual Laboratory, Internetbased, remote Teacher Online, facilitated virtual learning, synchronous, asynchronous, E-learning, superhighway, digital learning.

\subsection{The role of internet and social media on the language at the time of Covid 19}

Nowadays, people are very close to technology whether in real or virtual communication. Varnhagen et al (2009:270) show that online communication is a copy for real conversation but takes place in the written form at cyberspace with some changes in the form of writing.

Olaniran (2014:40) clarifies the fact that internet and social media have made a sensitive change in the way people communicate and the new expressions that have been produced to become part of every day's life expressions. Al-Obaydi and Ibrahim (2019:43) confirm this point by stating that using modern technology, in learning a new language help people and specially students to learn more quickly than they do in the traditional ways.

Baron (2001:21) points out that abbreviations are used as an economical way to insert more words on a single page and reduce writing time. He describes the world of online communication as "cyberspace" and for people who use this online world as "Netizens", whereas the language used as "net speak". Crystal (2006:8) adds that " Internet has encouraged a dramatic 
expansion in the variety and creativity of language" like short messages, using figures, emoticons, abbreviations, lack of formality and ,many other strategies.

Logan (2004:1-2) supports Crystal's idea of the impact of internet by referring to the deep changes of this new trend that appeared recently on various levels of language. He adds that the influence of internet on language goes beyond its original branches to change its functions, presentation and facilitates, especially in the rapid development of cyberspace which lead to developing the old language and emerge it as a new one.

Jovanovic (2013:46) illustrates that there are many changes that the virtual world has brought into the language and sometimes there is a necessity to come with some changes on language, since it is alive, needs to develop and refresh from time to time as well as have the ability to accept new words to be a part of it. He (ibid: 72) adds that "language would not be healthy if it stayed the same all the time".

\subsection{Grice's Maxims}

According to the philosopher H. P. Grice, it is essential to achieve the conditions of communication and follow his maxims in order to be a successful communicator. Surian et al (1996: 58- 59) illustrates that the idea behind these maxims is to expand the information and clarify the message more than influencing the others' actions. The essential and economic way to communicate with others is by following Grice's maxims.

Grice formulates four maxims to describe the way through which the conversation occurs as follows:

a. Maxim of Quantity: This maxim gives a high value to the obligation of the speaker to present the message in an informative way as much required and as far as possible; neither to give too little informative nor more than is required.

b. Maxim of Quality: This maxim occurs when the speaker is sincere; tells the fact and does not give information that lacks truthfulness and evidence.

c. Maxim of Relation: This maxim expresses the idea that the speaker makes the contribution very related and close to the topic; instead of talking about other topics, he gives direct answers.

d. Maxim of Manner: Through this maxim, the speaker should be obvious, direct, arranges the ideas, and avoids obscurity and ambiguity.

\subsection{Flouting the maxims}

In certain situations, people deliberately tend to flout the maxims to achieve certain aims. Martinich( 1980: 215) states the fact that in any conversation, whether in face to face or online conversation, people need to follow certain rules and maxims to be cooperative and do harmonious communication, so any violation of these rules leads the commenters to be uncooperative. 
Leech( 1983:7-8) clarifies the idea that people can flout these maxims whenever it is possible since it is not a standard or formal conversation, therefore, sometimes people deliberately conceal and violate the maxims through their daily conversation just to maintain social relationship.

Some times and for certain reasons, the commenter intentionally disobeys the rules of conversation flout maxims to convey positive or negative messages by using many words of (sarcasm or irony). There are certain rules in each culture and society that should be followed through any conversation but at certain occasions, but sometimes are flouted. Flouting the maxim serves the commenters just to get the intended meaning.

To sum up, Andresen (2013:4-6) expresses that any absent or nonobservance of one of these rules and maxims can be considered as a violation of the maxims and summarizes the process in five types:

a. Flouting. The speaker deliberately ignores one or more of the rules of conversation and cooperative principles, through which the speaker tries to convey other meanings without any intention to mislead others.

b. Violating. Through this type, the speaker intentionally tries to deceive and miss guide the listener by speaking the truth to imply the false.

c. Infringement. The speaker here tries, in a way or another, to follow the maxims but unintentionally, s/he conveys the wrong message according to the lack of understanding of others' question or disability or difficulty to communicate via the language of conversation.

d. Opting out of a maxim. The speaker here tries to violate the maxims and hide some information or give the right information for certain ethical or private reasons.

e. Suspending a maxim. The speaker realizes that what is said is far from truth due to certain reasons or events.

\subsection{Crystal's model}

Crystal (2001:52) defines language of internet as a form of written language used by people to communicate with each other via internet to reduce time and effort of writing and to be part of social media society. He mentions the following three vital strategies in online communication:

a. Graphology (emoticons, punctuation): it is a collection of figures for facial expressions or symbols, number and emoticons in the form of icons used by the commenters to convey their emotions, opinions and attitudes without using verbal words.

b. Deviation (abbreviations, acronyms): Through this criterion, the commenter tends to shorten words and substitute certain letters with others to write in a way that is different from the usual or common way via using some letters or short versions to refer to the original word, at the same time the commenter tries to write the first letter of each word to make a sign to refer to that word. Partey et al. (2018:26) shows that the reader may has a difficulty in reading these new word but on the other hand it is useful for the commenters themselves in reducing the effort 
and time of writing or when in a hurry via three techniques such as dropping or deleting a certain letters, using traditional abbreviation and using number and signs .

c. Formality (slang, formal) is the ability of the commenters to use certain nonstandard utterances or the arbitrarily changed words that belong to a specific group.

\section{Methodology}

\subsection{Data Collection}

The major aim of this study is to prove the idea that people tend to add certain strategies through their online comments and to achieve the aims of the study, the researchers collected 25 English patterns of social media comments from a number of academic and public pages. These comments are observed during five months in order to record the changes in the point of view of the commentators, if there is any, about online learning during the time of COVID 19. The researchers use social media to collect the data since they represent a new and effective way of communication.

\subsection{Models of analysis}

The study based on two adopted models; Grice's (1975) maxims (of qualitative ,quantitative, relevance and manner) and Crystal's (2001)model of online speech in terms of graphology (emoticons, punctuation)and deviation (abbreviations, acronyms), formality (slang, formal) and other criteria of net speak extensions). The researchers analyze the comments looking for whether the commentators follow or flout Grice maxims and Crystal's strategies through their face book comments.

\section{Findings}

'Context 1: "would you prefer continue teaching online once the covid-19 pandemic is over and why"?' This is a post through which the Facebook user tries to identify people's opinion about online learning and whether they will continue online teaching after the pandemic ends. The following comments have been posted as replies:

a. "It depends" the commenter expresses insincere opinion and conveys little information that do not convince others. This indicates that the commenter does not have enough information about the topic and never presents clear opinion. The commenter flouts the four maxims of Grice, since "It depends" never represents enough information, there is no evidence, ambiguous and irrelevant to the topic. According to Crystal's strategies, the commenter uses emoticons to express his/her opinion, and uses slang expressions.

b. "Not at all. Noooooo". Here, the commenter uses this ineffective comment, to show complete refusal, the response is not as informative as is required, so he flouts the all maxims of Grice and deviates Crystal's strategies through the word "noooooo". 
c. "As the pandemic will not be over for at least another 18 months, well do what I have to, one way or another". In the same context, the commenter is uninterested in this topic and there is a lack of evidence about the commenter agreement (quality). Less information (quantity) is given through this comment. The commenter flouts all the maxims except the maxim of relevance. According to Crystal's strategies, the commenter does not follow the formal strategies of writing and punctuations rules.

d. "No". This comment shows the negative impression about online learning, the comment does not give enough information, lacks evidence and is ambiguous. So the commenter flouts all the maxims and according, to Crystal's strategies, the commenter deliberately uses emoticons to express disagreement.

e. "Absolutely no". The face booker wants to assert his opinion by showing that he completely refuses online learning and indicate that there is no one cares for the topic. He does not apply quantity maxim and flouts the quality maxim and even does not follow Crystal's strategies.

f. "Well, I have been teaching online even before the pandemic". The comment shows that there is an interest in this topic previously and expresses regret on not using online learning previously. Grice's maxims are followed, but Crystal's strategies are not.

g. "I need someone to teach me English online", the comment might be considered as a request more than an answer to clarify personal's opinion about this topic, to show acceptance and get benefits. There is no enough information (flout the quantity maxim), there is no evidence (flout the quality maxim), the comment is so far from the topic (irrelevant), but the utterance is clear (manner). According to Crystal's model, the commenter does not follow the punctuation rules and never uses the other strategies.

h. "I've been teaching online 44 years be4 the pandemic. It's pretty effective. I'll definitely continue doing it". The commenter presents an explicit opinion, to show the agreement for using online learning even after the end of the pandemic with enough information (quantity). It reflects truth since there is a real life experience before the pandemic, in addition the comment is relevant and follow the manner maxim. Moreover the commenter uses the abbreviation as a strategy through writing the word (for) by using number (4).

i. "Yes". The commenter writes this word without showing her point of view just to be part of the conversation and agree about using online learning without mentioning the reasons; the comment does not represent enough information so there is a flouting of the maxims without following the strategies.

j. "Not entirely, but mostly face-to-face with occasional online where appropriate". The commenter follows the four maxims without using Crystal's strategies. The commenter expresses a confused opinion that she is preferred the blending of both. 
k. "A big NOOOOOO", This utterance expresses an underestimating of the topic, and the commenter shows a complete refusal towards the issue. According to Grice's maxims, the commenter gives less information than it is required, to follow the relevance and manner maxims while on the other hand there is no enough evidence for his refusal so he flouts the quality maxim. There is a clear deviation through writing the word "noo0000"

I. "No, I prefer face 2 face interaction It kind of connects us both teacher and students". The comment represents a complain about the new way of learning and show interest in traditional one, the commenter follows the four maxims in the comment, Besides, there is abbreviation through writing the number "2" instead of " to" and lack of punctuation marks.

m. "Definitely not but blended learning or flipped classroom may be introduced as an integral component', The commenter shows partial disagreement towards online learning alone but it could be possible to use it together with class room learning. So, there is no flouting of the maxims and no use of Crystal's strategies.

n. "The commenter here expresses her opinion by using confusing responses, she uses emoticon as a way of distinguishing her comment from others and refer to agreement, good relation, and could be meaningless by itself, so there is a need to be interpreted, therefore the comment flouts the maxims and uses semiotics as a strategy.

o. "Blending" the short comment indicates that the commenter prefers to learn through implementing online learning with traditional learning, so the comment is somehow confusing since there is no full agreement or full refusal. The user flouts the quantity and quality maxims and does not follow the strategies.

p. The commenter puts a smiling cat. The comment reflects a kind of sarcasm to answer an educational and important topic in this way. The commenter puts this cat in the comment to convey an ambiguous and meaningless message without giving a direct opinion, the reader will be confused whether the commenter agrees or not, so he flouts all the maxims of Grice and uses emoticons as a strategy.

q. "Yes, materials are ready I want to raise them for life. Hahaha". This utterance literarily seems normal, but it implies sarcasm concerning online learning and the comment's opinion is not clear. The commenter follows the quantity and relevance maxims but flouts the maxims of quality and manner.

r. "Hahaha No, not in a million years!!' is an informal language expression that makes; he uses the slang strategy alone. It is obvious through the comment that the commenter reflects her that he is never agrees to use online learning at any time. The comment flouts the quantity maxim since there is less information than is required, there is no evidence, so the 
quality maxim is flouted while the comment follows the rest of the maxims. According to Crystal, there is some use of punctuation marks.

s. "Totally YES! "Through this comment, the commenter expresses her full agreement and her interest in the topic without mentioning any reasons, also, she seems very convenience and directly expresses her optimism towards the future of learning. So she follows the quantity, relevance and manner maxims whereas she does not follow the maxim of quality. Also the comment involves nonverbal expressions with exclamations marks and there is a clear use of punctuation marks as a strategy and a semiotic

t. "yes and no..."This comment accepts two interpretations; agreement and refusal. It seems that the commenter agrees on the necessity of the topic at first, but then changes his opinion and refuses it. The comment confuses the readers. So it flouts the maxims and uses no strategy. Commenter agrees on the necessity of the topic at first, but then changes his opinion and refuses it. The comment confuses the readers. So it flouts the maxims and uses no strategy.

u. "I really enjoy online teaching but only teach 1-to-1 and 1-to-2. I was teaching $70 \%$ of my students online before the pandemic. All my f2f students subsequently moved over and all but one have said they prefer online tuition and are unlikely to return to f2f. My students all live rurally though, so the lack of travel may." It is clear that the commenter emphasizes the significant role of online learning although the obstacles it faces. It conveys a positive point of view about her student and how they prefer online learning for certain reasons. Thus, the opinion is very clear, so the commenter follows all the maxims as well as she uses the abbreviation $\mathrm{f} 2 \mathrm{f}$ and certain punctuation marks.

v. "Well I would nt mind a mix of both". The commenter shows that he is unsympathetic with online learning so he never wants to refuse the whole idea but it is a chance to make types of learning work together to get optimal results. Therefore the commenter flouts the maxims of quantity and quality but follows the relevance and manner maxims although the degree of relevance to the topic is not very clear, moreover he makes a violation in writing and punctuation marks.

w. "I am enjoying online teaching now with tons of tools but given the choice, no. I am a people person - I would integrate a few online tools with F2F teaching though". First of all, this comment is very similar to the previous one that the commenter expresses the fact that it is possible to use online learning now since there is no other solution but they will return to the traditional learning as soon as possible. There is a confusing opinion, so she follows the maxims through her opinion in this conversation. Beside that she uses some abbreviations and a figure to express her feelings towards the topic. 
x. 1 The commenter herself does not write anything but she substitutes that by using a picture to express indirectly the angry emotions towards online learning, the commenter prefers to show a confusing opinion, so there is no use of the maxims and there is a deviation of all the strategies.

y. "I am digressing but how much do they pay for online teaching and is it worth more than regular teaching job". The comment here is improper since the commenter deviates the discussion issue about education, to move to other financial related topic to confuse the readers. So he flouts the quantity, quality and relevance maxims and follows only the maxim of manner. Besides, he does not follow any strategy.

Table 1. The Frequencies and Percentages of following and flouting Grice's (1975) maxims and Crystal's (2001) strategies

\begin{tabular}{|c|c|c|c|c|c|c|c|c|c|}
\hline \multirow[t]{2}{*}{ Maxims } & \multicolumn{2}{|c|}{ Following Maxims } & \multicolumn{2}{|c|}{ flouted maxims } & \multirow[t]{2}{*}{ strategies } & \multicolumn{2}{|c|}{ using strategies } & \multicolumn{2}{|c|}{$\begin{array}{l}\text { never use } \\
\text { strategies }\end{array}$} \\
\hline & Frequency & $\begin{array}{c}\text { Percentage } \\
\%\end{array}$ & $\begin{array}{l}\text { freque } \\
\text { ncy }\end{array}$ & $\begin{array}{c}\text { Percen } \\
\text { tage } \\
\%\end{array}$ & & frequency & $\begin{array}{c}\text { Perc } \\
\text { entag } \\
e \\
\% \\
\end{array}$ & $\begin{array}{l}\text { frequ } \\
\text { ency }\end{array}$ & $\begin{array}{c}\text { Percen } \\
\text { tage } \\
\%\end{array}$ \\
\hline Quantity & 9 & $36 . \%$ & 16 & $64 \%$ & $\begin{array}{c}\text { Grapholog } \\
y \\
\text { (semo.)+( } \\
\text { pun) }\end{array}$ & 12 & $48 \%$ & 13 & $52 \%$ \\
\hline Quality & 6 & $24 \%$ & 19 & $76 \%$ & $\begin{array}{l}\text { Deviation( } \\
\text { abbr.) }\end{array}$ & 7 & $28 \%$ & 18 & $72 \%$ \\
\hline Relevance & 14 & $56 \%$ & 11 & $44 \%$ & $\begin{array}{c}\text { formality } \\
\text { (slang) }\end{array}$ & 4 & $16 \%$ & 21 & $84 \%$ \\
\hline Manner & 14 & $56 \%$ & 11 & $44 \%$ & & & & & \\
\hline Total & 43 & & 57 & & Total & 23 & & 52 & \\
\hline
\end{tabular}

\section{Discussion}

In the light of the analysis of the data, the researchers prove that the two adopted models are applicable. The data also, show that most people prefer to flout the maxims and never give direct answers, females in general, prefer to combine their comments with semiotic items since their comments are affected by certain factors such as the context of situation, the post itself and other's comments. Moreover, using semiotics and deviation of punctuation marks are the most frequently used strategies, to show that most commenters prefer formal language. Ultimately, Commenters tend to combine their expressions with many figures and semiotics just to emphasize their opinions. Maxims and strategies are flouted many times in most comments and sometimes, more than one maxim is flouted in a single comment. 
Throughout the study, the results of the analysis show that some maxims are flouted more than others and the maxim of quality is the most flouted maxim while the maxims of manner and relevant is the least one. As with Crystal's strategies, more than half of commenters use formal language and graphology, semiotic and punctuation have the highest frequency in these strategies, while slang language and abbreviation strategies are the least used strategy. Some commenters use certain linguistic changes through their comments such as omitting definite articles and pronouns. Some of them prefer to use emoticons while others use abbreviations or combines more than one strategy.

Throughout the analysis, it is found that the commenters present different forms of opinions via using various expressions which is created by Facebook comments about the online learning. $28 \%$ of commenters give the sincere opinion about the crucial role of online learning at this emergency time, $8 \%$ show sarcasm of the topic for certain reasons for instance; the lack of skills in this new trend and the great benefits of school, so they directly express their opinion that ordinary learning is more appropriate than distant learning , 36\% seem confused and are not interested in showing their opinions, they comment just to maintain social relations and $28 \%$ seem pessimistic and show negative opinions.

\section{Conclusions}

Most people tend to use the abbreviation, variation words and spelling just to interact with others briefly, in simple way and quickly. There is a great influence for the contextual variants, situation whether formal or informal, the degree of relationship between the interlocutors on the ability to select the appropriate forms of comments. There are little differences in the way of commenting between males and females. That most females prefer to add semiotic and pictures.

The most flouted maxim is the quality maxim, since the commenters tend to make their comments shorter or longer than it is required to obtain certain purposes. While the maxim of manner and relevant are the least one. Formality is the most followed strategy It is worth mentioning that through the analysis, both of Grice and Crystal model are applicable. Commenters are affected by other's comments.

The majority of people tend to use these figures in informal posts with words to convey the intended meaning of the commenter if they are used correctly in the suitable place and time. People's point of view of online learning has been changed concerning .E-learning within the passage of time. Eventually, Most of English commenters follow the simple, short and direct expressions to show their opinions.

\section{References}

Al-Obaydi, Liqaa and Ibrahim, Atyaf (2019) The Effect of Viber Application on the Acquisition of Clipped, Blended and Acronym Words. The Online Journal of Quality in Higher Education - January 2019Volume 6, Issue 1. 
Andresen, N. (2013) Flouting the Maxims in Comedy: An Analysis of Flouting in the Comedy Series Community. Master Thesis. Department of Language, Literature and Intercultural Studies.

Anderson,T. (2008) The Theory and Practice of Online Learning. Athabasca University. 2nd edition. AU press

Baron, N. (2001) Language Of The Internet In Stanford Handbook For Language Engineers. Ali Farghali(Ed) Stanford California: CSLI Publications, 1-63. Center for the Study of Language and Information.

Baten, L. Stijn V and Bert De. C. (2009) Learning: a Pragmatic Framework for 2nd Generation E-Learning Projects. Information and Communications Technologies (ICT 2009).RePEc

Crystal, D. (2001).Language and the Internet. New York. Cambridge University press.

Faisal, A. Samir, M. Iqbal, S.M. and Yasin, M. (1999) Effectiveness Of Cyber Learning. Karachi, Pakistan. 9th ASEE/ IEEEF rotifers in (Education Conference13a28). Institute of electrical and electronic engineers.

Grice, H.(1975) Logic and Conversation. In Cole, p. and Morgan, J. L. (Eds). Speech Acts. New York: Academic press.

Jovanovic, D. (2013) A Qualitative Study of the Use of Net Speaks in English Language Classroom. (Master thesis).

Kollock, P. and Smith, M. (1999) Communities in Cyberspace. London: Rutledge

Leech, G. (1983) Principles of Pragmatics. London: Longman

Logan, R. (2004) The Sixth Language: Learning a Living in the Internet Age. University of Toronto. Toronto press.

Malhotra,S. \& Goyal,A.(2013) Role of Online Education in Modern Education System. E-Vaani: An International Journal of Research in Management \& IT. Volume: 1, NO: 1. ISSN No. 2348 1536.6.195.

Martinich, A. P. (1980) Conversational Maxims and Some Philosophical Problems. The Philosophical Quarterly (1950).Vol. 30, No. 120, pp. 215228 . Oxford University Press

Olaniran ,S.(2014) Social Media And Changing Communication Patterns Among Students. Covenant Journal of Communication (Cjoc), Vol. 2, No. 1. university Of Jos, Nigeria

Othman, M. , Mohamad, N., Yusuf, L., Yusof, N., and Suhaimi, S. (2012) An Analysis of e-Learning System Features in Supporting the True eLearning. 2.0. Procedia - Elsevier Ltd. Social and Behavioral Sciences 56, $454-460$.

Partey, F. ,Rosemary, G.Addo-Danquah, Lucy, K.B. and Kwasi S.(2018) Investigating Unconventional Abbreviations In sms Texts. International Journal of Applied Linguistics \& English literature E-ISSN: 2200-3452 \& PISSN: 22003592.IJALEL. 
Pozgaj, Z. and knezevic, B. (2007) E-Learning: Survey on Students' Opinions. 10.1109/ITI.2007.4283800.Conference: Information Technology Interfaces, 2007. ITI 2007. 29th International Conference.

Prensky,M.(2001) Digital Native .Digital Immigrants .On the Horizon,9(5),1-6

Surian, L. Simon B.C. and Heather V. der L. (1996). "Are Children with Austin Deaf to Gricean Maxims?" Cognitive neuropsychiatry. Psychology Press (UK): Taylor \& Francis Ltd. Vol. 1, No. 1,1996: P.P.55-71.

Surjono, H.D. Ali, M. and Wahyuningsih, D .(2017). The Implementation of Blended Learning in Multimedia Courses for Undergraduate Students in Indonesia. International Journal of Information and Education Technology, Vol. 7, No. 10, October 2017

Varnhagen, Connie K., McFall, G. Peggy and Pugh, Nicole, Routledge, Lisa; Sumida MacDonald, Heather and Kwong, Trudy E. (2010) lol: New Language and Spelling in Instant Messaging. An Interdisciplinary Journal, v23 n6 p719-733 Jul 2010 Connie. Routledge, Lisa. ERIC. 